\title{
A desaceleração do processo de Reforma dos Cuidados de Saúde Primários
}

Raquel Braga*

$\mathrm{T}$ odos temos vindo a sentir que o processo de reforma dos Cuidados de Saúde Primários está a desacelerar, como se estivesse prestes a ser suspenso, por falta de liderança, de ideologia ou de recursos.

No entanto, a implementação das Unidades de Saúde Familiar (USF) foi a única referência positiva inserida no Memorando da Troika, na área da eficiência no sector da saúde. ${ }^{1}$

Apesar de a tónica ser colocada «no reforço dos serviços de cuidados de saúde primários, de modo a continuar a redução do recurso desnecessário a consultas de especialidade e às urgências e de modo a melhorar a coordenação dos cuidados, através de: i. aumento do número das Unidades de Saúde Familiares (USF) contratualizadas com Administrações Regionais de Saúde (ARS), continuando a recorrer a uma combinação de pagamento de salários e de pagamentos baseados no desempenho", as USF em modelo A que já obtiveram parecer positivo da Equipa Regional de Apoio (ERA) para passagem a modelo B continuam a aguardar, em vão, a recompensa pelo esforço efectuado, consubstanciado pelo adiar sine die da assinatura da carta de compromisso com as ARS e/ou Unidades Locais de Saúde (ULS).

Isto depois de estas USF já terem sido submetidas a um controlo extremamente rigoroso de qualidade, eficiência e desempenho, através de grelhas sucessivamente mais exigentes, que as colocam num patamar praticamente sobreponível às USF modelo $\mathrm{B}$, mas sem a retribuição por desempenho inerente.

Em Março de 2013, conforme legislado, foi emitido um Despacho conjunto dos Ministérios das Finanças e da Saúde, ${ }^{2}$ estabelecendo o número de USF a constituir, no corrente ano. Nesse despacho, é referido «que as

*Directora da Revista Portuguesa de Medicina Geral e Familiar
USF têm vindo a contribuir de forma significativa para a melhoria da acessibilidade, da cobertura assistencial, da eficiência económica e, sobretudo, da qualidade efetiva dos cuidados de saúde prestados à população, considera-se imprescindivel o reforço do modelo de USF.»²

No entanto, são apontados limites máximos ao invés de serem recomendados números mínimos para as novas USF a criar (69), e a transitar de modelo (20). ${ }^{2}$

Desde o pico de 2009, em que houve a entrada em funcionamento de 71 novas USF, esse valor diminuiu nos anos seguintes, para 47,42 e $36 .^{3}$ No ano de 2013, até Setembro, apenas 17 USF entraram em funcionamento, quando a média foi de 48 por ano, nos 7 anos anteriores, e a recomendação do despacho conjunto seria de 69 novas USF. Houve, portanto, diminuição nos últimos anos, quando as expectativas e necessidades previam um aumento.

Neste momento, há diversas USF a aguardar a passagem a modelo $B$, já com parecer técnico da ERA emitido. No Norte, onde este modelo é mais prevalente, são 8 que aguardam homologação e 8 que estão em candidatura. Um número equivalente de USF passou a modelo B em 2013, mas todas referentes a pareceres emitidos em 2012.

De alguns lados, estranhamente, algumas das vozes que explicitamente apoiaram e desenvolveram a filosofia da Reforma proposta pela Missão para os Cuidados de Saúde Primários (MCSP) e levaram à implementação no terreno das USF insinuam agora que afinal ela não parece ser assim tão custo-efectiva, que é possível fazer o mesmo ou talvez ainda mais, com modelos de Unidades de Saúde que consideravam anteriormente menos desenvolvidos por terem menor grau de maturidade organizacional e nível de desempenho... Esta forma de análise, pouco sustentada por estudos de viabilidade económica ou de outra natureza técnico-científica, é contrária aos princípios funda- 
mentais defendidos pela MCSP, ao que a Troika recomenda $^{1}$ e àquilo que o Governo de Portugal, por esta via de intervenção externa, é aconselhado a reforçar.

Os dados de estudos de viabilidade económica e de custo-efectividade deste modelo em Portugal são escassos e na sua maioria produzidos pelas próprias USF. Um estudo profundo, alargado e isento seria necessário para reforçar inequivocamente uma linha de orientação.

Em Maio de 2013, foi apresentado no Encontro Nacional das USF, em Lisboa, o estudo realizado pela Associação Nacional de USF em parceria com a Administração Central do Sistema de Saúde (ACSS). No entanto, que se saiba, estranhamente, este estudo ainda não foi publicado. No seu artigo «Trabalhar melhor - o Exemplo das USF»4, João Rodrigues comenta que, segundo os resultados deste estudo, o modelo das USF tem um impacto positivo em termos de acessibilidade às consultas médicas em geral, e em particular às consultas de Planeamento Familiar, bem como nas taxas de cobertura dos rastreios de cancro da mama e colo-rectal. Para além destes indicadores, o modelo USF associa-se a um incremento da vigilância de doentes diabéticos e hipertensos, condicionando avultadas poupanças em medicamentos e meios complementares de diagnóstico prescritos.

Os resultados deste estudo demonstram "o valor do modelo USF através dos resultados obtidos, nas áreas do acesso, do desempenho, da qualidade e da eficiência, significativamente melhores do que os alcançados pelas unidades tradicionais, destacando-se sobretudo o acesso geral, o acesso a cuidados domiciliários, vigilância da doença crónica e oncológica, precocidade na vigilância da grávida e recém-nascido e eficiência económica". ${ }^{4}$

Esta posição é corroborada por André Biscaia, médico de Família e doutorado em políticas de saúde e desenvolvimento, na sua entrevista à Revista da Ordem dos Médicos, ${ }^{5}$ em que comenta a existência de evidência robusta de que as USF, em particular o seu modelo $\mathrm{B}$, mais exigente, com maior autonomia e melhores resultados, fomentam a qualidade, facilitam o acesso e desenvolvem a racionalidade na prescrição, constituindo também importantes centros de formação e de investigação. $^{5}$

Apesar dos bons indícios e dos resultados concretos, parece haver um impasse por parte da tutela em decidir o que pretende - avançar com a reforma desenha- da pela MCSP ou pelo contrário interromper esta reforma e apresentar outro modelo?

Parece haver um pensamento contraditório acerca do que os Ministérios da Saúde e das Finanças esperam das USF (cada vez mais empenho, qualidade, autonomia e rigor) e aquilo que as ARS e ULS estão dispostas a dar (cada vez menos autonomia, cada vez menos recursos, protelar do pressuposto e necessário pagamento por desempenho).

Esta ambiguidade nas intenções e paralisia na acção está a tornar-se insustentável e as equipas que estão no terreno e que lutam por se organizar e desenvolver desmotivam-se, cansadas de perseguir objectivos demasiado ambiciosos e desgastantes, sem qualquer incentivo.

Desta forma, dadas as grandes exigências que o modelo B condiciona, o retorno das USF que aguardam homologação após parecer positivo da ERA a uma prática clínica com menores pressões nos objectivos de contratualização e mais tempo para garantir outro tipo de qualidade de cuidados, não centrados nos actuais indicadores de saúde, com mais tempo para outras tarefas assistenciais, actualmente não contratualizadas e que foram, em alguns casos, inevitavelmente sendo colocadas em segundo plano, pode ser bastante adequado e apelativo. Seria o retorno de várias Unidades que aspiravam à transição prevista pela Reforma a modelos menos desenvolvidos, seguramente menos retribuídos, mas que podem conferir aos profissionais garantias de menores pressões a nível de cumprimento de objectivos, menos responsabilidades organizacionais, ou seja, outro tipo de qualidade de vida e outra forma de satisfação profissional, já que os pressupostos do contrato não estão a ser garantidos e que o modelo das UCSP também tem de ser acarinhado e demonstra obter resultados satisfatórios. ${ }^{6}$

Claro que, idealmente, deveríamos ter uma generalização dos incentivos em toda a área dos cuidados primários e, logo que possível, a todo o Serviço Nacional de Saúde, tal como afirma o actual Secretário de Estado, Leal da Costa, em entrevista recente. ${ }^{6}$

Depois de tecer estas considerações acerca da falta de incentivo à implementação e desenvolvimento das USF, que não premeia o esforço de quem se tem empenhado no que lhe foi demandado, o que é completamente contrário ao que está recomendado pela actual conjectura, resta-me salientar que, após uma longa jor- 
nada iniciada em 2005, que mesmo tendo levantado dúvidas e questões, demonstrou ser caminho bem construído, com ganhos em saúde, aumento da satisfação e da autonomia dos profissionais e em algumas áreas inclusive com aumento da satisfação dos utentes, seria de esperar que a Reforma tomasse um rumo seguro, sustentado e sustentável. Porquê este impasse ou este retrocesso?

Se há provas de que este não é o melhor caminho, que alguém o diga claramente e tenha a coragem de mostrar e propor que há um caminho melhor.

\section{REFERÊNCIAS BIBLIOGRÁFICAS}

1. Memorando de Entendimento sobre as Condicionalidades de Política Económica. Disponível em: http://www.portugal.gov.pt/media/ 371372/mou_pt_20110517.pdf [acedido em05/07/2013].

2. Ministérios das Finanças e da Saúde. Despacho n.o 4586-A/2013, de 1 de Abril. Disponível em: http://dre.pt/pdf2sdip/2013/04/063000001/ 0000200002.pdf

3. USF. Disponível em: http://www.acss.min-saude.pt/DepartamentoseUnidades/UnidadePlaneOrganizaçãodeServiçosdeSaúde/Cuidados-
deSaúdePrimários/ACES/USF/tabid/770/language/pt-PT/Default.aspx [acedido em 05/07/2013].

4. Rodrigues J.Trabalhar melhor - o exemplo das USF. MGFamiliar. - Monday, June 24, 2013. Disponível em: http://www.mgfamiliar.net/_blog/ MaisOpinião_-_João_Rodrigues/post/jro/ [acedido em 05/07/2013].

5. Entrevista a André Biscaia. O ministro da Saúde parece ainda não acreditar nas USF. Rev Ordem Médicos 2013 Jul-Ago; 142: 46-52. Disponível em: http://issuu.com/revistaordemdosmedicos/docs/142 [acedido em 05/07/2013].

6. Entrevista a Fernando Leal da Costa: "Este Governo pretende assegurar um médico de família para todos os que o desejarem". NewsFarma. Disponível em: http://www.newsfarma.pt/artigos/76 [acedido em 07/09/2013].

\section{CONFLITO DE INTERESSES}

A autora declara pertencer a uma USF em modelo A que já obteve parecer positivo da ERA para passagem a Modelo B e que aguarda homologação. Declara ainda ter sido Presidente do Conselho Clínico do ACeS de Matosinhos na Unidade Local de Saúde de Matosinhos até Fevereiro de 2013.

\section{ENDEREÇO PARA CORRESPONDÊNCIA}

director@rpcg.apmcg.pt 